\title{
Galectin-1 Accumulation in the Ovary Carcinoma Peritumoral Stroma Is Induced by Ovary Carcinoma Cells and Affects Both Cancer Cell Proliferation and Adhesion to Laminin-1 and Fibronectin
}

\author{
Frédéric van den Brûle, Stéphane Califice, Frédérique Garnier, Pedro L. Fernandez, \\ Andrew Berchuck, and Vincent Castronovo \\ Metastasis Research Laboratory (FvdB, SC, FG, VC) and Department of Gynecology (FvdB), University of Liège, \\ Liège, Belgium; Hospital Clínic and Institut d'Investigacions Biomèdiques "August Pi i Sunyer" (PLF), University of \\ Barcelona, Barcelona, Spain; and Duke University Medical Center (AB), Durham, North Carolina
}

SUMMARY: Galectin-1 (gal-1) is a 14-kDa laminin-binding galectin involved in several biologic events including regulation of cancer cell proliferation and adhesion to the matrix. In this study, we examined gal-1 expression in 30 human epithelial ovary carcinoma samples by Western and Northern blotting and by immunohistochemistry. Gal-1 mRNA levels were increased in more than $95 \%$ of the examined ovary carcinoma samples, compared with a wedge resection of a normal ovary. Immunohistochemical analysis of the samples demonstrated gal-1 expression in cancer epithelial cells from 17 of 30 samples, with a cytoplasmic pattern. Gal-1 immunostaining was significantly increased in the stroma associated with carcinoma cells compared with the normal, noninvaded stroma $(p=0.003)$. This pattern of expression was confirmed by examination of 12 other frozen epithelial ovary carcinomas, using in situ hybridization. Immunohistochemical staining of the specimens demonstrated colocalization of gal-1, laminin-1, and fibronectin. In vitro experiments were conducted to elucidate the potential biologic role of gal-1 in ovarian cancer progression. Gal-1 protein expression and release was detected in AZ364, SK-OV-3, and AZ224, but not in OVCAR-3, AZ419, and AZ382, human ovary carcinoma cell lines. Incubation of 84BR fibroblasts with conditioned media harvested from the ovary carcinoma cell lines induced an increased expression of gal-1 in the cultured fibroblasts in all cases except AZ419 and SK-OV-3. High concentrations of gal-1 (100 $\mu \mathrm{g} / \mathrm{ml}$ ) induced significantly decreased cell proliferation in all cell lines, as defined by bromodeoxyuridine incorporation. Additionally, recombinant gal-1 induced a dose-dependent increase in in vitro adhesion of AZ224, SK-OV-3, and AZ382 cells to laminin-1; adhesion to fibronectin was increased by gal-1 in OVCAR-3, AZ224, and SK-OV-3. No effect was observed in the other cases. Our data contribute to define a role for gal-1 during the interactions between human ovary carcinoma cells and host fibroblasts. (Lab Invest 2003, 83:377-386).

$T$ he galectins constitute a growing family of soluble lactose-binding lectins sharing affinity for $\beta$-galactoside residues and significant sequence similarity in their carbohydrate-binding site (Barondes et al, 1994). A large body of literature has described their possible involvement in numerous biologic events related to carbohydrate recognition during cell-cell and cell-matrix interactions. Galectin-1 (gal-1), a pleiotropic homodimeric protein whose $14-\mathrm{kDa}$ monomer is almost exclusively composed of a carbohydrate

\section{DOI: 10.1097/01.LAB.0000059949.01480.40}

Received September 26, 2002.

$F v d B$ is a Research Associate and SC is the beneficiary of a Télévie grant of the National Fund for Scientific Research, Belgium. This work was supported by the National Fund for Cancer Research (Belgium), the Léon Frédéricq Foundation (Liège, Belgium), and the Fondo de Investigaciones de la Seguridad Social (Spain).

Address reprint requests to: Dr. F. van den Brûle, Metastasis Research Laboratory, Pathology B23, Sart Tilman, B-4000 Liège 1, Belgium. E-mail:f.vandenbrule@ulg.ac.be recognition domain, is involved in cell-cell and cellmatrix interactions (Barondes et al, 1994; Cooper, 1997). Indeed, this lectin promotes adhesion of normal and cancer cells to laminin (Ellerhorst et al, 1999; Mahanthappa et al, 1994; van den Brûle et al, 1995; Zhou and Cummings, 1990) as well as to other biologic components (Ahmed et al, 1992; Stojanovic et al, 1983). These biologic phenomena are probably related to the homodimeric structure of gal-1. Proliferation of normal and malignant cells is modulated by gal-1: growth inhibition is observed at high gal-1 concentrations, whereas lower concentrations of gal-1 induce a stimulation of cell proliferation (Adams et al, 1996). Other functions of gal-1 have also been highlighted, such as participation in the process of pre-mRNA splicing (Vyakarnam et al, 1997). Gal-1 also induces apoptosis of activated T cells, through binding to cell surface CD45 (Perillo et al, 1995) and CD7 molecules (Pace et al, 2000), a property that could protect the cancer cells against T-cell immune response. 
Expression of gal-1 in malignant tumors has been examined in various cancer types. Increased gal-1 expression has been demonstrated in human cancers, including those arising from thyroid (Chiariotti et al, 1992, 1995; Xu et al, 1995), endometrium (van den Brûle et al, 1996), head and neck (Gillenwater et al, 1996), thymus (Hafer-Macko et al, 1996), bladder (Cindolo et al, 1999), pancreas (Berberat et al, 2001), and colon (Sanjuan et al, 1997) and those such as cholangiocarcinoma (Shimonishi et al, 2001) and glioma (Rorive et al, 2001). Gal-1 was also described in the stroma associated with cancer cells (Gillenwater et al, 1996; Sanjuan et al, 1997). We recently demonstrated that preferential accumulation of gal- 1 in the stroma associated with prostate carcinoma cells is related to progression of the disease (van den Brûle et al, 2001).

In this study, we examined gal- 1 expression in a collection of human ovary carcinoma samples, and we observed significantly increased expression of gal-1 in the stroma adjacent to carcinoma cells, compared with noninfiltrated stroma. We then conducted in vitro experiments to better understand this phenomenon and its influence on the behavior of ovary carcinoma cells.

\section{Results \\ Expression of Galectin-1 in Human Ovary Carcinoma Samples}

We first examined gal-1 expression in 30 human ovary carcinoma samples by Northern and Western blotting and by immunohistochemistry. The gal- 1 mRNA message was detected in all of the ovary carcinomas RNA samples on Northern blots. Analysis of the Northern blotting data demonstrated that more than 95\% (25 of 26) of the samples showed increased glyceraldehyde3-phosphate dehydrogenase (GAPDH)-normalized gal-1 mRNA levels when compared with an RNA sample extracted from a wedge resection from a normal ovary. Western blotting experiments using the anti-gal-1 antibody showed a single 14-kDa band in all of the ovary carcinomas samples (Fig. 1, A to C), as expected (van den Brûle et al, 1996). The results of gal-1 detection from the Northern and Western blotting and from immunohistochemistry experiments (Fig. 1, A to C) showed the best correlations in the more cellular tumors, mainly because of the heterogeneity in some of the examined tissues and the fact that gal- 1 is also found in normal cells and in the stroma.
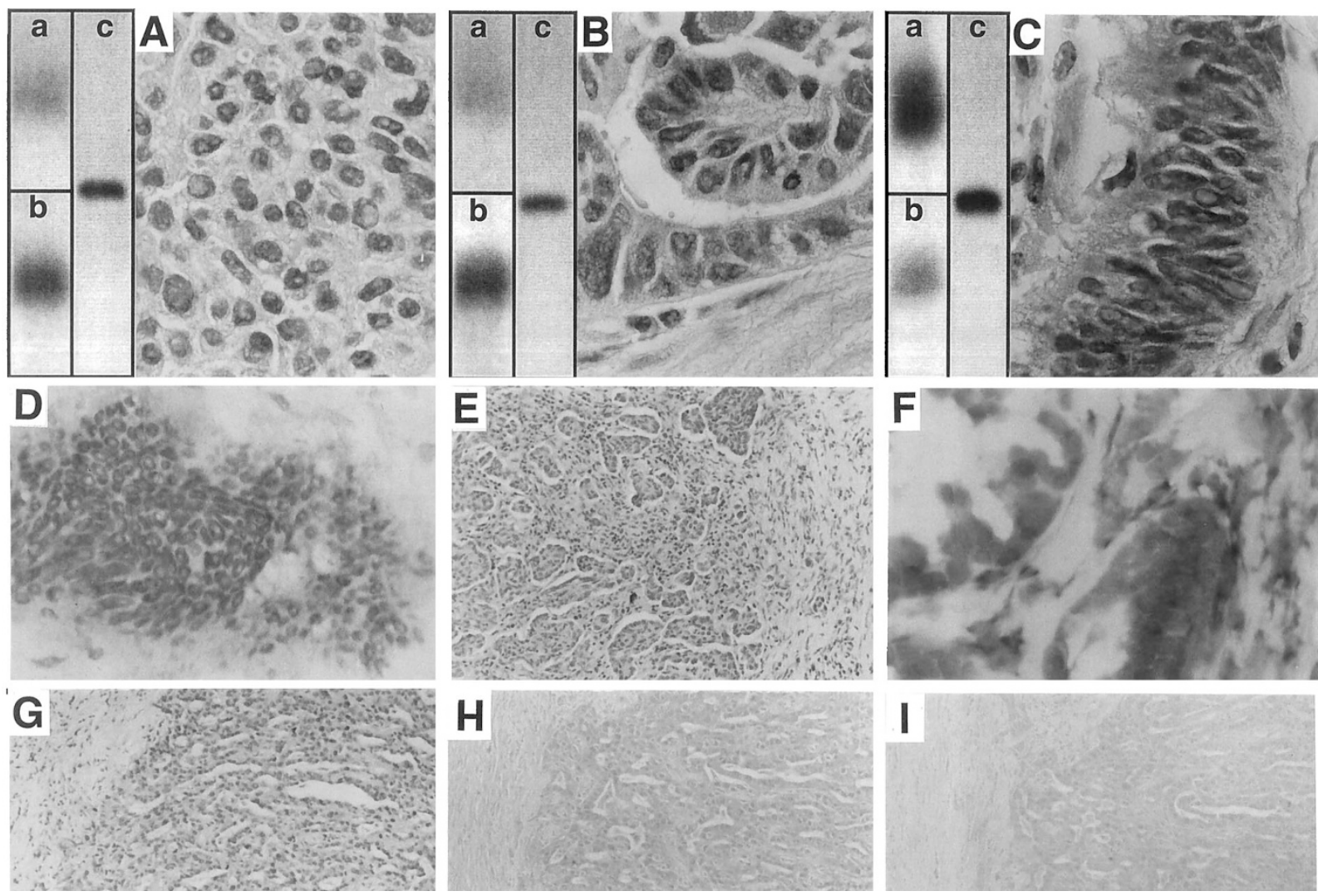

\section{Figure 1.}

Expression of galectin-1 (gal-1) in human ovary carcinoma samples and colocalization with laminin-1 and fibronectin. A to C, Typical examples of gal-1 expression in human ovary carcinomas, as determined by Northern blotting using the gal-1 (a) and glyceraldehyde-3-phosphate dehydrogenase (b) cDNA probes, by Western blotting (c), and by immunohistochemistry (right part of the panels A to C, and panels D and E). Serous carcinomas expressing low and high levels of gal-1 are respectively shown in $A$ and $B$; $C$ shows a mucinous carcinoma. D, gal-1 positivity is found in invading carcinoma cells and in the adjacent stroma. $E$, An example of strong positivity of the stroma infiltrated by the carcinoma cells (left part of the panel), compared with the stroma that is not invaded (right part of the panel). $F$, (In situ hybridization) strong, predominant mRNA expression of gal-1 in stroma cells and moderate expression into the carcinoma cells. The last three panels show an example of colocalization of gal-1 (G), laminin-1 (H), and fibronectin (I). Original magnification: $\times 630$ (A to $C), \times 400$ (D and F), and $\times 100$ (E and $G$ to I). 
Because of its cell type specificity, immunohistochemistry was considered as the most reliable detection technique, allowing discrimination between normal and neoplastic tissue. Gal-1 expression was heterogeneous from sample to sample. Cancer cells and stroma were often positive. Tumor epithelial cells were clearly positive in 17 of the 30 cases, with a cytoplasmic pattern. Statistical analysis of the data revealed that gal-1 expression was significantly higher in mucinous carcinomas compared with serous tumors $(2.33$ $\pm 0.58, n=3$, vs $0.66 \pm 0.77, n=19, p=0.027$, Wilcoxon-Mann-Whitney test; Fig. 1).

In some samples, gal-1 could be detected in both invading carcinoma cells and their surrounding stroma (Fig. 1, E), suggesting release of the lectin. Examination of the stroma associated with the carcinoma cells demonstrated that it was positive for gal-1 immunostaining in a large majority of samples (score 1 in 20 of 24 cases). However, the stroma associated with the normal tissue, when present on the slide, was characterized by low or absent immunostaining (score 0 in 9 of 9 cases). Statistical analysis demonstrated a significant increase of gal- 1 expression in the stroma adjacent to carcinoma cells compared with the stroma that was not infiltrated by the carcinoma cells $(0.83 \pm$ $0.38, n=24$, vs $0 \pm 0, n=9, p=0.003$, WilcoxonMann-Whitney test; Fig. 1E). To verify gal-1 mRNA expression by the different cell types, we also conducted in situ hybridization on 12 other frozen epithelial ovary carcinoma samples (Fig. 1F). Expression of gal-1 mRNA was predominantly found in stromal cells close to carcinoma cells, in all samples; moderate staining was also observed in carcinoma cells. No other correlation between gal-1 expression (determined by immunohistochemistry) and available clini- copathologic features of the ovary carcinomas samples could be established.

\section{Colocalization of Galectin-1, Laminin-1, and Fibronectin in Ovary Carcinoma}

We also examined the presence of laminin-1 and fibronectin in carcinoma cell-associated stroma in 35 ovary carcinoma samples by immunohistochemistry, because it is known that cancer cells express and secrete these molecules (Christensen, 1992; Hunt, 1989). The majority of the cases showed conspicuous colocalization of gal-1, laminin-1, and fibronectin (Fig. 1 , G to I). Twenty cases $(57.1 \%)$ presented with conspicuous accumulation of gal- 1 in the cancerassociated stroma, whereas 21 and 15 showed positivity for laminin-1 and fibronectin, respectively. Of the 20 cases that were positive for gal- 1 in the cancer cell-associated stroma, $16(80 \%)$ and 12 (60\%) were also positive for laminin-1 and fibronectin, respectively. Statistical analysis of these data revealed correlation coefficients of 0.471 and 0.400 between stromal gal-1 and either laminin-1 or fibronectin ( $p=$ 0.0038 and 0.0166 , respectively).

\section{Expression of Galectin-1 in Human Ovary Carcinoma Cell Lines}

We first examined gal-1 expression in six human ovary carcinoma cell lines by Western blotting (Fig. 2, upper left pane/). Gal-1 was detected in the AZ364, SK-OV-3, and AZ224 but not in the OVCAR-3, AZ419 and AZ382 cell extracts. Because gal-1 exerts interactions with extracellular matrix components, we examined cell surface expression of gal-1 in the cell lines by flow
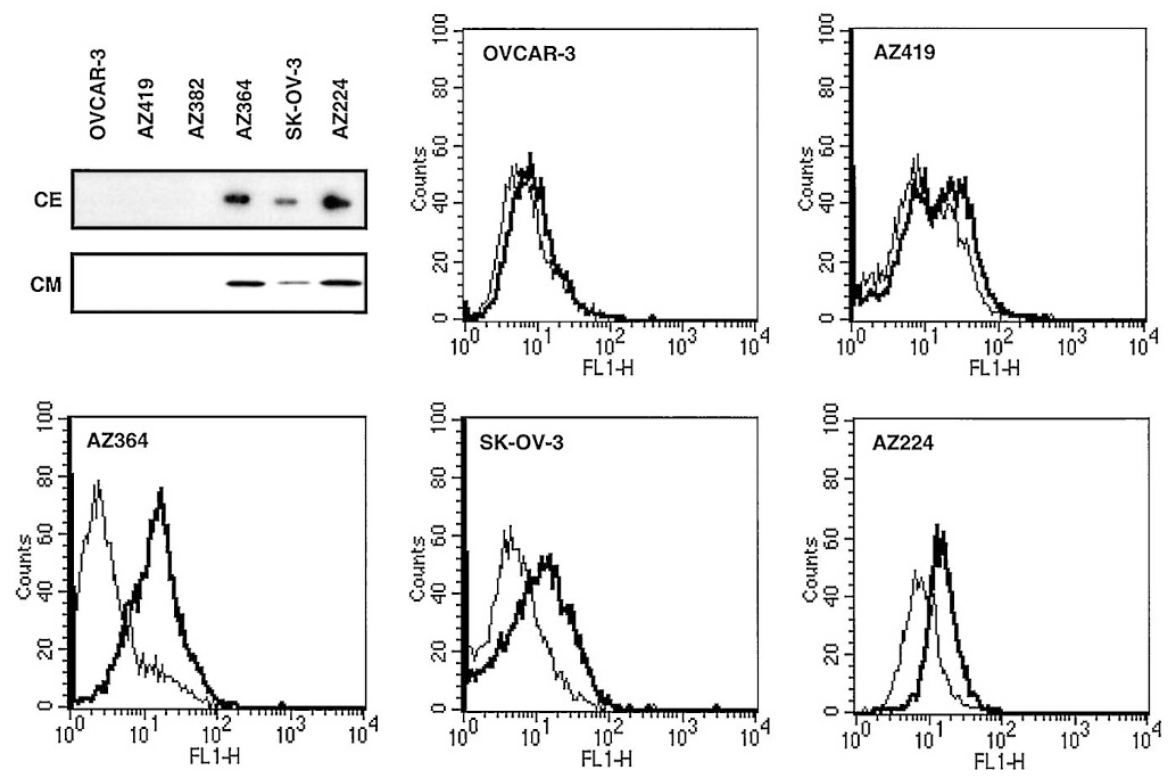

Figure 2.

Expression of gal-1 protein in ovary carcinoma cell lines. Gal-1 detection was performed using Western blotting in six ovary carcinoma cell lines (upper left panel) in both cell extracts $(C E)$ and in $\times 70$ concentrated conditioned media $(C M)$. Detection of gal-1 on the surface of live cells was performed using flow cytometry, and the resulting data are presented as histograms (other panels). No data are presented for the AZ382 cell line, which could not be analyzed by flow cytometry because of its propensity to form cell aggregates. The data correspond to the incubation of the ovary carcinoma cells without (thin lines) or with the anti-gal-1 antibody (thick lines). Counts = number of events; $F L 1-H=$ fluorescence intensity. See "Materials and Methods" for details. 
cytometry (Fig. 2). No results could be obtained for the AZ382 cell line, because it formed cell clumps that could not be resolved to single-cell suspension. A shift of fluorescence intensity was observed with the three cell lines that were positive for gal-1 expression by Western blotting, ie, AZ364, SK-OV-3, and AZ224; the three other cell lines were negative. Because we observed gal-1 in the stroma surrounding ovary carcinoma cells in the pathologic specimens, we concentrated $(\times 70)$ the conditioned media $(\mathrm{CM})$ using Centricon devices and observed the presence of gal- 1 in those/the CM harvested from the three gal-1-positive cell lines. However, crude, nonconcentrated CM as well as the pass-through filtrate fractions from the Centricon procedure did not show the presence of gal-1 by Western blotting (not shown).

\section{Effect of Ovary Carcinoma-Derived CM on Galectin-1 Expression in Human Fibroblasts}

Because we observed that fibroblasts surrounding cancer cells were positive for gal- 1 immunostaining, we tested the possibility that host fibroblasts could constitute a source of gal-1 in the cancer cell-associated stroma. Western blotting analysis demonstrated that cell extracts from in vivo-grown 84BR fibroblasts show gal-1 expression; we also observed the presence of the lectin in the $\times 70$ concentrated 84BR CM (Fig. 3A), consistent with gal-1 release from the fibroblasts.

To determine whether the ovary carcinoma cells could modulate gal-1 protein expression in the surrounding fibroblasts of the stroma, we treated human 84BR fibroblasts for 48 hours with various ovary carcinoma cell CM. Gal-1 expression was determined by Western blotting and quantified (Fig. 3B). Incubation with OVCAR-3, AZ224, AZ364, and AZ382 CM reproducibly increased gal-1 protein expression in the 84BR fibroblasts. No modulation was observed when the 84BR fibroblasts were treated with AZ419 and SK-OV-3 CM. The observed modulations cannot be explained by the presence of gal- 1 in the $\mathrm{CM}$, because OVCAR-3- and AZ382-concentrated CM are characterized by the absence of gal-1 (Fig. 2).

\section{Modulation of Human Ovary Carcinoma Cell Incorporation of Bromodeoxyuridine (BrdU) by Galectin-1}

It has already been demonstrated in other models that gal-1 modulates cell growth (Adams et al, 1996). We thus tested the effect of recombinant gal- 1 on the proliferation of ovary carcinoma cell lines using a BrdU incorporation assay. Two experimental protocols were used. In the first one, cells were seeded in plates and immediately incubated with gal-1 for 48 hours. In the second protocol, the cells were cultured in complete medium for 1 day and then incubated with gal- 1 for 48 hours as above. Similar results were obtained with these two types of experiments and were averaged to generate Figure 4. Low concentrations of recombinant gal-1 did not significantly affect BrdU incorporation; higher concentrations $(100 \mu \mathrm{g} / \mathrm{ml})$ induced a signifi-

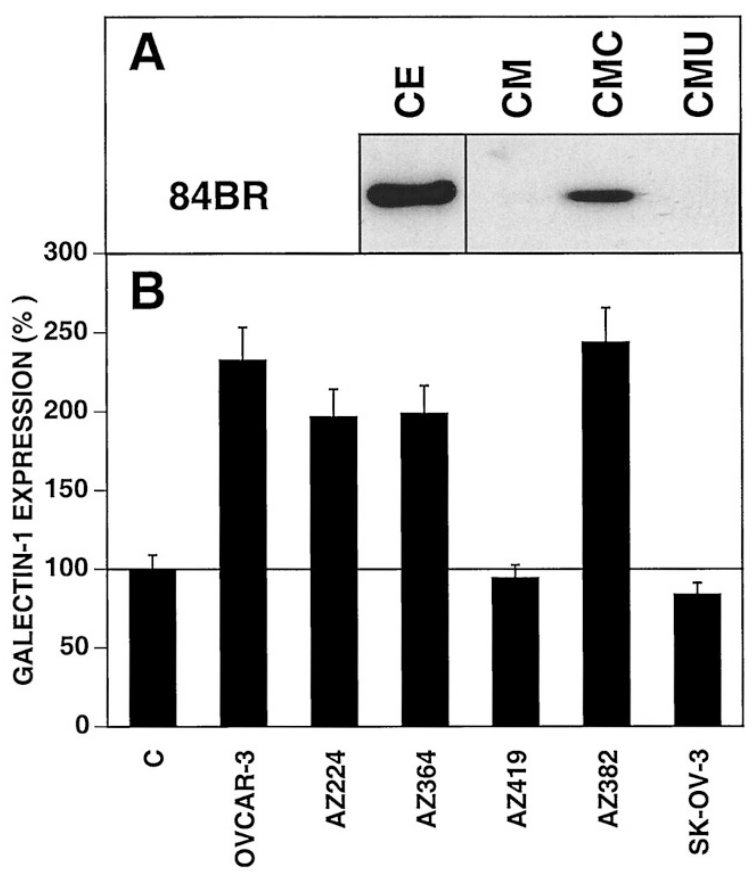

Figure 3.

Expression, release, and modulation of gal-1 expression in 84BR fibroblasts by ovary carcinoma CM. Gal-1 was detected by Western blotting in cell extracts $(C E)$ and $\times 70$ concentrated conditioned medium $(C M C)$ but not in crude conditioned medium or the pass-through filtrate from the concentration procedure (CMU) (A). After incubation of the fibroblasts for 48 hours with ovary carcinoma cell-conditioned medium, fibroblast extracts were analyzed by Western blotting and the blots were analyzed by densitometric analysis as described in "Material and Methods." The values obtained in the examined conditions were divided by the control value (ie, incubated with nonconditioned medium; $C$ ). Values used in the bar graph (B) correspond to the mean \pm SD of three independent experiments.

cant decrease in BrdU incorporation in all six ovary carcinoma cell lines (Fig. 4).

\section{Modulation of Human Ovary Carcinoma Cell Attachment to Laminin-1 and Fibronectin by Galectin-1}

Because our data demonstrate the presence of gal-1 in the stroma surrounding the ovary carcinoma cells, we examined the effect of recombinant gal- 1 on the ability of ovary carcinoma cell lines to adhere onto laminin-1 and fibroblast fibronectin. The adhesion profiles of the examined cell lines were first determined (Fig. 5A). The free-floating cells (AZ419 and AZ382) did not show significant adhesion to laminin-1 or fibronectin; adhesion to laminin-1 reached $30 \%$ (AZ364) and adhesion to fibronectin reached $100 \%$ (OVCAR-3) after 120 minutes. Then, the effect of recombinant gal-1 on cell adhesion was evaluated. Addition of increasing concentrations of gal-1 ( 0 to $400 \mu \mathrm{g} / \mathrm{ml}$; Fig. 5B) induced a dose-dependent increase in adhesion to laminin-1 in AZ224 and AZ382 cells, and to a lesser extent in SK-OV-3 cells (maximum fold increase in attachment value after a 30 minute incubation period, 2.87, 6.19, and 1.81, respectively). No significant effect was observed in OVCAR-3, AZ364, and A419 cells. Adhesion to fibronectin after 30 -minute incubation was increased by 

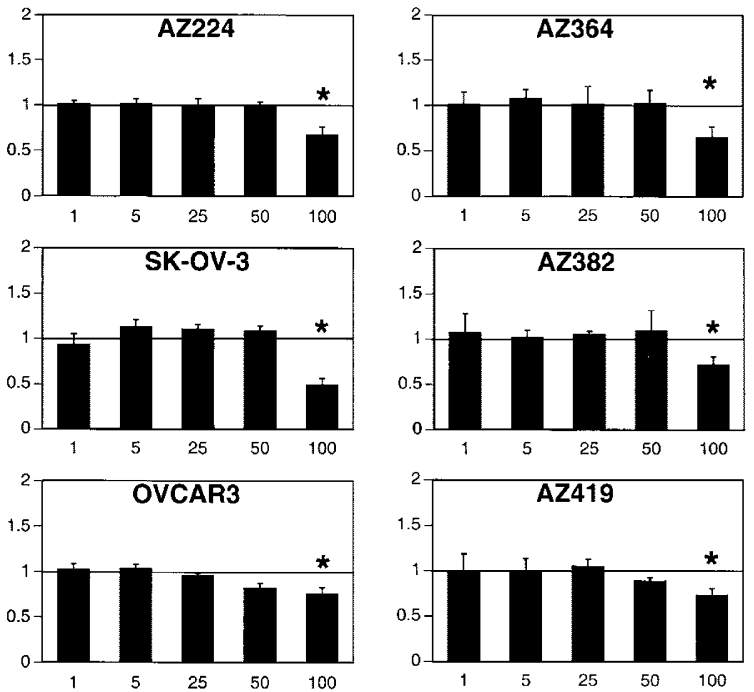

Figure 4.

Gal-1 modulates ovary carcinoma cell proliferation. Cell proliferation was assessed using a bromodeoxyuridine incorporation assay, in the presence of increasing amounts of recombinant gal-1 $(x$ axis; $\mu \mathrm{g} / \mathrm{ml})$. The results are expressed as percentage of the control value (ie, without addition of gal-1). ${ }^{*} p$ $<0.05$ (Student's $t$ test). See "Materials and Methods" for details.

addition of gal- 1 in OVCAR-3 cells (5.4-fold); moderate increases were observed in AZ224 and SK-OV-3 cells (1.5- and 1.7-fold, respectively). No modulation of adhesion was observed in AZ364, AZ382, and AZ419 cells.

\section{Discussion}

Our study demonstrates that gal-1 expression is increased in human ovary carcinoma tissues. This observation is in agreement with previous reports of gal-1 overexpression in other malignant lesions (Berberat et al, 2001; Chiariotti et al, 1992, 1995; Cindolo et al, 1999; Gillenwater et al, 1996; Hafer-Macko et al, 1996; Rorive et al, 2001; Sanjuan et al, 1997; Shimonishi et al, 2001; van den Brûle et al, 1996; Xu et al, 1995). Recently, another example of gal-1 mRNA overexpression was provided in a androgenindependent LNCaP variant compared with the parental, androgen-dependent cell line (Vaarala et al, 2000).

In ovary carcinoma, gal- 1 preferentially accumulates in the adjacent peritumoral stroma. Although such an accumulation has also been reported in the stroma surrounding thyroid (Xu et al, 1995), head and neck (Gillenwater et al, 1996), colon (Sanjuan et al, 1997), and prostate carcinoma (van den Brûle et al, 2001), the mechanisms responsible for this phenomenon and its consequences on tumor progression have not been investigated. We therefore conducted experiments to elucidate the mechanisms that lead to gal-1 accumulation in the stroma adjoining ovary cancer cells. Using in situ hybridization experiments, we clearly demonstrated that fibroblast cells, adjacent to the malignant cells, express gal-1 mRNA and contribute, at least in part, to gal-1 accumulation. Ovary carcinoma cells likely intervene also in this process because we observed that they express gal-1 mRNA
A
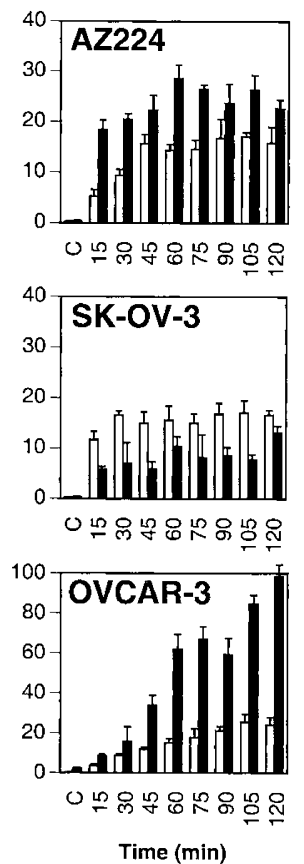

B
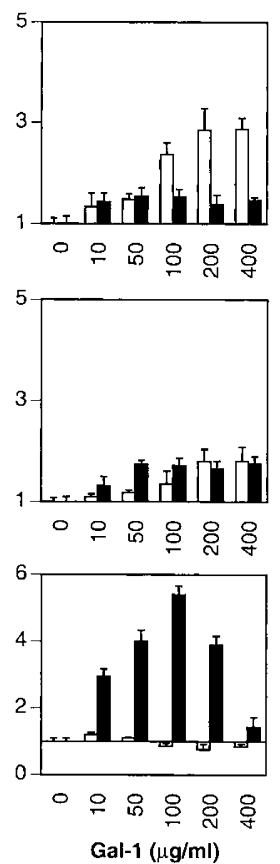

A
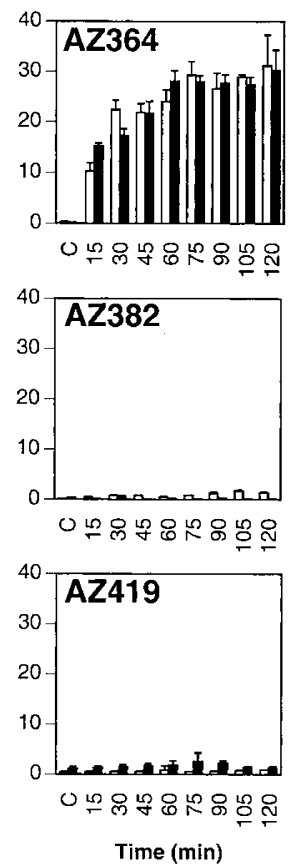

B
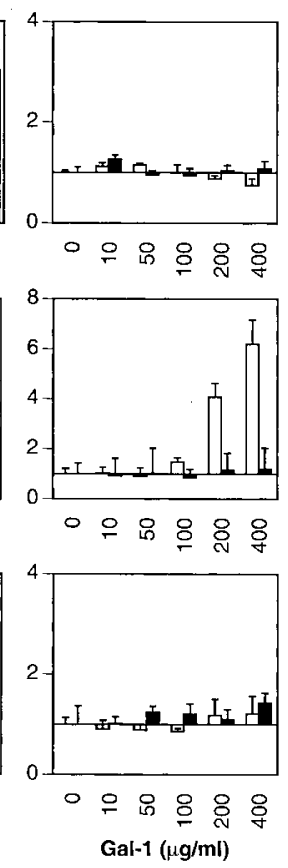

Figure 5.

Modulation of ovary carcinoma cell attachment to laminin-1 (open bars) and fibroblast fibronectin (closed bars) by gal-1. Adhesion values ( $y$ axis, expressed as percentages of the cells) according to time of incubation ( $x$ axis, minutes) of adherent (AZ224, SK-0V-3, OVCAR-3, and AZ364) and free-floating (AZ382 and AZ419) ovary carcinoma cells were determined (A). C, incubation of the cells for 30 minutes onto BSA-coated wells, without laminin- 1 . The effect of addition of gal- 1 at determined concentrations ( $x$ axis, $\mu \mathrm{g} / \mathrm{ml}$ ) to the cells before incubation was determined at 30 minutes of incubation. 
and release the corresponding protein into the medium.

The observation that fibroblasts immediately adjacent to the ovary cancer cells were more positive for gal-1 at both the mRNA and protein levels compared with distant fibroblasts suggested that the malignant cells might be responsible for their gal-1 expression. Such a hypothesis was supported by the demonstration that conditioned medium obtained from ovary carcinoma cells induced an increased gal-1 expression in 84BR fibroblasts.

We then demonstrated that gal-1 accumulated in the cancer-associated stroma can decrease cell proliferation and modulate cell adhesion to laminin-1. The first event could be viewed as a defense mechanism from the host against the tumor, because stromal gal-1 could contribute to decreased cancer cell proliferation in vivo.

Although the decreased cell proliferation induced by gal-1 was observed in all six tested cell lines, promotion of cell adhesion to laminin-1 or fibronectin by gal-1 was found in three of the six cell lines. Cell line selectivity was neither related to gal-1 expression in the cell lines nor to their ability to attach to plastic. Gal-1, as a homodimeric molecule (Bourne et al, 1994; Liao et al, 1994), is likely to bridge immobilized laminin-1 to glycoconjugates located on the cell surface, such as laminins and/or Lamps. The known expression of those molecules in cancer cells and their ability to bind galectins (van den Brûle and Castronovo, 2000) could be the reason for this specificity of cell behavior. Our observations suggest that gal-1 accumulated at the border between the cancer cells and the host stroma could modulate these interactions and hence promote invasion. Stromal gal-1 could also decrease proliferation of the fibroblasts in an autoand paracrine fashion (Adams et al, 1996) and, as a consequence, impair the host reaction to circumvent the tumor by creating a fibrous capsule to restrain its progression.

Another putative role for gal-1 accumulated around the tumor could be the modulation of the local antitumor immune response. Indeed, gal-1 modulates TCR signals (Vespa et al, 1999) and cytokine production (Rabinovich et al, 1999) and induces apoptosis of activated $T$ lymphocytes through binding to the polylactosamine-enriched CD45RO (Perillo et al, 1995) and CD7 (Pace et al, 1999). Gal-1 could therefore constitute an immunologic shield that protects cancer cells against host immune response.

The global effect of these biologic events for tumor progression is likely to result from a balance between "negative" events, such as decreased ovary cancer cell proliferation, and apparently favorable effects for tumor progression, including promotion of cancer cell adhesion and defense against host immune response. The relative importance of all these elements, and the positive or negative global effect for tumor progression, could be different depending on the tumor type. We already demonstrated a positive correlation between preferential accumulation of gal- 1 in cancerassociated stroma and progression of prostate cancer (van den Brûle et al, 2001). Thus, more detailed evaluation of the prognostic significance of this parameter in other human cancers as well as of the role of gal-1 in cancer progression is mandatory.

In conclusion, our findings demonstrate increased expression of gal-1 in human ovary carcinoma cells and preferential accumulation in cancer-associated stroma, a finding that could be important for cancer progression. These data support a role for gal- 1 in the crosstalk between cancer cells and the associated stroma and in modulation of the biologic behavior of the cancer cells. The influence of host-derived versus cancer cell-derived gal-1 on cancer progression remains to be further elucidated.

\section{Materials and Methods}

\section{Ovary Carcinoma Tissue Samples}

Two groups of ovary carcinoma samples were examined. The first was used for Northern and Western blotting experiments and for immunohistochemistry. Thirty-five samples of human ovarian carcinoma samples were obtained from the Department of Gynecological Oncology (Duke University Medical Center, Durham, North Carolina) (van den Brûle et al, 1994). Thirty samples were examined for gal- 1 expression by immunohistochemistry. Twenty-six samples were from primary tumors and four from recurrences (obtained after primary treatment including chemotherapy). For each sample, clinicopathologic data with histologic type and grade were available. In the group, there were 20 serous and 3 mucinous tumors (other types: $n=7$ ); the majority $(n=17)$ of the tumors were moderately differentiated, and 9 were poorly differentiated. Surgical staging was established according to the FIGO staging system (International Federation of Gynecology and Obstetrics, 1987). There were 2 Stage I, 4 Stage II, 18 Stage III, and 6 Stage IV carcinomas. Colocalization of gal-1, laminin-1, and fibronectin was examined by immunohistochemistry in slides from the 35 paraffin blocs.

The second group, consisting of 12 liquid nitrogen frozen, TEK-embedded epithelial ovary carcinoma samples, was obtained from the Tumors and Tissue Bank of the Department of Anatomic Pathology, Hospital Clinic Provincial, Barcelona.

\section{Northern and Western Blotting}

Total cellular RNA was extracted from the powdered frozen tissue samples. Of the 30 samples, 23 were sufficient to allow RNA extraction by guanidine isothiocyanate lysis-cesium chloride cushion centrifugation (Glisin et al, 1974). Northern blotting was performed according to standard procedures using gal-1 (van den Brûle et al, 1995) and GAPDH (Ercolani et al, 1988; Piechaczyk et al, 1984) probes. X-ray films were exposed and quantified using the public domain $\mathrm{NIH}$ Image 1.62 software program for the Apple Macintosh (developed at the United States National Institutes of Health and available at http://rsb.info.nih.gov/nih-im- 
age/). The normalized gal-1/GAPDH ratios were used as values for subsequent analyses.

Total protein extracts were performed in 1\% SDS from the 24 largest powdered tissue samples. Fifteen micrograms of protein extract, as determined by a bicinchoninic acid protein assay (MicroBCA; Pierce Chemical Company, Rockford, Illinois), were separated by size on $15 \%$ SDS-polyacrylamide gels, transferred to a polyvinylidene difluoride membrane (PVDF; Immobilon, Millipore Corporation, Brussels, Belgium). Western blotting was performed using an affinitypurified rabbit polyclonal anti-recombinant gal-1 antibody (a gift from D. N. W. Cooper, University of California at San Francisco, California) (Cooper and Barondes, 1990) and a chemoluminescence reaction procedure (Roche, Brussels, Belgium). If needed, signal quantification was performed using NIH Image, as described above.

\section{Immunohistochemistry}

Immunoperoxidase staining of gal-1 was performed in paraffin sections of 27 formalin-fixed samples of ovary carcinoma with the above-described anti-gal-1 antiserum (Cooper and Barondes, 1990), which was extensively characterized for specificity (van den Brûle et al, 1996, 2001). The avidin-biotin peroxidase complex method was used as previously described (Hsu et al, 1981; van den Brûle et al, 1996) (ABC Vectastain Elite Kit; Vector Laboratories, Burlingame, California). Briefly, sections were deparaffinized in xylene and rehydrated in PBS (10 mm sodium phosphate, 0.9\% $\mathrm{NaCl}, \mathrm{pH} 7.5)$. Blocking of the endogenous peroxidase was performed with $0.3 \% \mathrm{H}_{2} \mathrm{O}_{2}$ in methanol, and the nonspecific serum-binding sites were saturated with normal goat serum. The slides were incubated for 2 hours at room temperature with the diluted anti-gal-1 antiserum, for 30 minutes with the secondary biotinylated antibody, and then with the biotinylated horseradish peroxidase complex. Peroxidase activity was revealed by the 3,3'-diaminobenzidine tetrahydrochloride reaction (Graham and Karnovsky, 1966), and sections were finally counterstained with hematoxylin. Staining of the slides was evaluated by three independent observers in a blinded fashion, using an arbitrary semiquantitative scale: 0 , negative; 1 , focal areas with sparse staining or occasional individual positive cells; 2 , at least one focus with extensive staining or numerous areas with weak to moderate staining; and 3, extensive staining of more than $50 \%$ of the neoplastic cells. Immunostaining was also examined in the stroma infiltrated by the carcinoma cells and in the noninfiltrated stroma; it was evaluated by an arbitrary scale as follows: 0 , absence of staining or positivity in $<50 \%$ of the evaluable stroma; and 1 , positivity in more than $50 \%$ of the evaluated stroma. The evaluations of gal-1 immunostaining by the three observers were alike, and their mean was used in the statistical tests. The differences between the values of various groups of ovarian carcinoma specimens were determined by the nonparametric double-sided WilcoxonMann-Whitney test, using the Statview statistics soft- ware package for the Macintosh (SAS Institute Inc., Cary, North Carolina). The specificity of the antibody was assessed by omission of the first antibody (not shown). Immunostaining of 35 ovary carcinoma samples from the first examined group was also performed using rabbit anti-laminin-1 and guinea pig antifibronectin polyclonal antisera, kindly provided by Professor J.-M. Foidart (University of Liège, Belgium). Evaluation of the positivity of the stroma located around the carcinoma cells was performed as described above. Correlation coefficients were calculated using Statview.

\section{In Situ Hybridization}

The presence of gal-1 mRNA transcripts in primary ovary cancer samples was demonstrated by a nonradioactive in situ hybridization technique, as previously described (van den Brûle et al, 1999). The antisense and sense riboprobes were synthesized using a DIG RNA labeling kit and T7 polymerase (Roche) from the F14-3AS and F14-4S plasmids as previously described (van den Brûle et al, 1999). Specificity controls included observation of the absence of staining using sense probes in each case. In addition, AZ224 and OVCAR-3 epithelial ovary carcinoma cells were used as positive and negative controls, respectively, as previously described (van den Brûle et al, 1999).

\section{Cell Lines, Tissue Culture, and CM}

Human Caov-3, SK-OV-3, and OVCAR-3 epithelial ovary cancer cell lines were obtained from the American Type Culture Collection (Rockville, Maryland) and routinely grown in DMEM supplemented with $10 \%$ fetal bovine serum (FBS) (Caov-3), McCoy's 5a supplemented with 15\% FBS (SK-OV-3), or RPMI 1640 with $10 \mu \mathrm{g} / \mathrm{ml}$ insulin and 10\% FBS (OVCAR-3). The AZ224, AZ364, AZ382, and AZ419 ovary carcinoma cell lines were obtained from Dr. Jacques de Grève (Academisch Ziekenhuis, Vlaamse Universiteit Brussel, Brussels, Belgium). The two latter cell lines grow as free-floating cells, and the others are adherent cell lines. The AZ224 cell line was grown in RPMI 1640 supplemented with $20 \%$ FBS and $100 \mathrm{IU} / \mathrm{ml}$ glutamine; the AZ364, AZ382, and AZ419 cell lines were grown in RPMI 1640 supplemented with $10 \%$ FBS and $250 \mathrm{~nm}$ dexamethasone. CM were collected as follows. After extensive rinses with PBS, preconfluent ovary carcinoma cells were incubated for 48 hours in FBS-free DMEM. The CM was collected and centrifuged to remove cell debris and stored at $-80^{\circ} \mathrm{C}$ until use. Concentration was performed using Centricon YM-10 centrifugal filter devices (molecular weight cut off, 10,000 D; Amicon, Millipore, Brussels, Belgium). The $\mathrm{CM}$ were checked for $\mathrm{pH}$ and glucose and lactate concentrations before treatment of the 84BR fibroblasts to examine gal-1 modulation of expression and to verify that the $\mathrm{pH}$ values were in the 7.2 to 7.4 range, that glucose concentrations varied between 3.0 and $3.8 \mathrm{~g} / \mathrm{L}$, and that the lactate concentrations were below $600 \mathrm{mg} / \mathrm{L}$. 
The 84BR fibroblast cell line was obtained from the European Tissue Culture Collection (ECACC, Salisbury, United Kingdom) and was grown in MEM supplemented with 15\% FBS and 1\% nonessential amino acids. Antibiotics $(100 \mu \mathrm{g} / \mathrm{ml}$ penicillin, $100 \mu \mathrm{g} / \mathrm{ml}$ streptomycin) were added to all culture media. The cell lines were grown in a humidified atmosphere of $5 \%$ $\mathrm{CO}_{2} / 95 \%$ air at $37^{\circ} \mathrm{C}$. All tissue culture reagents were obtained from Life Technologies (Merelbeke, Belgium). CM were harvested and concentrated as described above.

\section{Flow Cytometry}

Ovary carcinoma cell lines were analyzed for expression of gal-1 at the cell surface by flow cytometry. Briefly, ovary carcinoma cells were harvested using 2 mM EDTA in calcium-magnesium-free PBS. One million cells were suspended at $5 \times 10^{6} \mathrm{cells} / \mathrm{ml}$ in HBSS (GibcoBRL, Life Technologies) in a total volume of 200 $\mu l$ and incubated with diluted anti-gal-1 polyclonal antibody (1/5000) (Cooper and Barondes, 1990) for 30 minutes at $4^{\circ} \mathrm{C}$ (thick lines, Fig. 2). Control cells were incubated similarly but without primary antibody (thin lines, Fig. 2). The cells were washed twice in HBSS and incubated with an anti-rabbit IgG FITCconjugated secondary antibody (dilution 1/160; Sigma, Bornem, Belgium) for 30 minutes at $4^{\circ} \mathrm{C}$. After two washes, cell surface fluorescence was analyzed using a FACSCalibur cytometry unit (Becton Dickinson, Erembodegem, Belgium). A scatter window was set to eliminate dead cells and cell debris, and the results were presented as histograms.

\section{Treatment of Human Fibroblasts with CM from Ovary Carcinoma Cells}

To explore the possible interactions between the ovary carcinoma cells and the fibroblasts, we tested the influence of CM collected from ovary carcinoma cell lines on the two types of fibroblasts. Preconfluent fibroblasts were incubated with ovary carcinoma CM for 48 hours. After this time, protein extracts were performed using 1\% SDS and processed for Western blotting using the anti-gal-1 antibody as described above. The values obtained in the examined conditions were divided by the control value (ie, fibroblasts incubated with nonconditioned medium). Three independent experiments were conducted, and the means and SD were calculated.

\section{Cell Proliferation Assay}

The effect of IA-treated recombinant gal-1 on ovary carcinoma cell proliferation was assessed as follows. Ten thousand ovary carcinoma cells were seeded in each well of 96-well plates; the cells were allowed to attach and were incubated overnight at $37^{\circ} \mathrm{C}$ in $200 \mu \mathrm{l}$ of their usual culture medium. After overnight incubation, the culture medium was removed, the cells were thoroughly washed with PBS, and recombinant gal-1 diluted at specified concentrations in $200 \mu \mathrm{l}$ DMEM was added to the cells. Cell proliferation was mea- sured after 48-hour treatment, using a colorimetric assay based on the measurement of BrdU incorporation during DNA synthesis, according to the manufacturer's protocol (Roche). In another set of experiments, 6000 cells were seeded in each well in complete growth medium, allowed to attach, and cultured 1 day in DMEM before adding recombinant gal-1 diluted in DMEM containing $2 \%$ FBS. The statistical significance of the results was determined using the Student's $t$ test.

\section{Attachment of Ovary Carcinoma Cells to Laminin and Fibronectin}

Attachment assays were performed as described (van den Brûle et al, 1995). Briefly, Immulon I Removawell strips (Dynatech Labs, Chantilly, Virginia) were coated overnight at $37^{\circ} \mathrm{C}$ with $10 \mu \mathrm{g}$ purified EngelbrethHolm-Swarm laminin-1 or human fibroblast fibronectin (Calbiochem-Merck, Leuven, Belgium), washed with PBS, and blocked for 1 hour with 1\% BSA. After trypsinization and a 2-hour recovery period, 50,000 cells labeled overnight with $\left[{ }^{35} \mathrm{~S}\right]$ methionine ( $\operatorname{Tran}^{35} \mathrm{~S}$ Label; ICN, Irvine, California) and resuspended in serum-free medium containing $0.1 \%$ BSA were added to the wells. The cells were incubated in a $5 \% \mathrm{CO}_{2} /$ $95 \%$ air incubator at $37^{\circ} \mathrm{C}$ for specified periods of time. The assay was stopped by aspiration of the media and three gentle washes with PBS; attached cells were lysed in $1 \%$ SDS, and the percentage of attached cells was determined by scintillation counting and comparison to the radioactivity of 50,000 labeled cells. In other experiments, recombinant gal-1 was added to the cells at specified concentrations, and the attachment values were evaluated after 30minute incubation. Recombinant gal-1 was purified by lactose affinity chromatography and alkylated using iodoacetamide to prevent oxidation as previously described (Cooper et al, 1991). The attachment values obtained were divided by the corresponding control values, ie, without addition of gal-1. All experiments were conducted in quadruplicates and were reproduced at least three times.

\section{Acknowledgments}

We thank Dr. D. Cooper (University of California at San Francisco, California) for providing the anti-gal-1 antiserum, Professor J.-M. Foidart (University of Liège, Belgium) for the anti-laminin-1 and antifibronectin antisera, Dr. J. Ordi from Hospital Clínic of Barcelona for the collection of some samples, and Ms. A.-M. Ferir (University of Liège, Belgium) for the determination of glucose and lactate concentrations in the conditioned media. The authors thank Pascale Heneaux for expert technical assistance.

\section{References}

Adams L, Scott GK, and Weinberg CS (1996). Biphasic modulation of cell growth by recombinant human galectin-1. Biochim Biophys Acta 1312:137-144. 
Ahmed H, Sharma A, DiCioccio RA, and Allen HJ (1992). Lymphoblastoid cell adhesion mediated by a dimeric and polymeric endogenous $\beta$-galactoside-binding lectin (galaptin). J Mol Recognit 5:1-8.

Barondes SH, Cooper DNW, Gitt MA, and Leffler H (1994). Galectins: Structure and function of a large family of animal lectins. J Biol Chem 269:20807-20810.

Berberat PO, Friess H, Wang L, Zhu Z, Bley T, Frigeri L, Zimmermann A, and Buchler MW (2001). Comparative analysis of galectins in primary tumors and tumor metastasis in human pancreatic cancer. J Histochem Cytochem 49:539549.

Bourne Y, Bolgiano B, Liao DI, Strecker G, Cantau P, Herzberg O, Feizi T, and Cambillau C (1994). Crosslinking of mammalian lectin (galectin-1) by complex biantennary saccharides. Nat Struct Biol 1:863-870.

Chiariotti L, Berlingieri MT, Battaglia C, Benvenuto G, Martelli ML, Salvatore P, Chiappetta G, Bruni CB, and Fusco A (1995). Expression of galectin-1 in normal human thyroid gland and in differentiated and poorly differentiated thyroid tumors. Int J Cancer (Pred Oncol) 64:171-175.

Chiariotti L, Berlingieri MT, De Rosa P, Battaglia C, Berger N, Bruni CB, and Fusco A (1992). Increased expression of the negative growth factor, galactoside-binding protein, gene in transformed thyroid cells and in human thyroid carcinomas. Oncogene 7:2507-2511.

Christensen $L$ (1992). The distribution of fibronectin, laminin and tetranectin in human breast cancer with special attention to the extracellular matrix. APMIS Suppl 26:1-39.

Cindolo L, Benvenuto G, Salvatore P, Pero R, Salvatore G, Mirone V, Prezioso D, Altieri V, Bruni CB, and Chiariotti L (1999). Galectin-1 and galectin-3 expression in human bladder transitional-cell carcinomas. Int J Cancer 84:39-43.

Cooper DNW (1997). Galectin-1: Secretion and modulation of cell interactions with laminin. Trends Glycosci Glycotechnol 9:57-67.

Cooper DN and Barondes SH (1990). Evidence for export of a muscle lectin from cytosol to extracellular matrix and for a novel secretory mechanism. J Cell Biol 110:1681-1691.

Cooper DN, Massa SM, and Barondes SH (1991). Endogenous muscle lectin inhibits myoblast adhesion to laminin. J Cell Biol 115:1437-1448.

Ellerhorst J, Nguyen T, Cooper DN, Lotan D, and Lotan R (1999). Differential expression of endogenous galectin-1 and galectin-3 in human prostate cancer cell lines and effects of overexpressing galectin-1 on cell phenotype. Int $\mathrm{J}$ Oncol 14:217-224.

Ercolani L, Florence B, Denaro M, and Alexander M (1988). Isolation and complete sequence of a functional human glyceraldehyde-3-phosphate dehydrogenase gene. J Biol Chem 263:15335-15341.

Gillenwater A, Xu X-C, El-Naggar AK, Clayman GL, and Lotan $R$ (1996). Expression of galectins in head and neck squamous cell carcinoma. Head Neck 18:422-432.

Glisin V, Crkvenjakov R, and Byus C (1974). Ribonucleic acid isolated by cesium chloride centrifugation. Biochemistry 13: 2633-2637.

Graham C and Karnovsky MJ (1966). The early stages of absorption of horseradish peroxidase in the proximal tubules of mouse kidneys: Ultrastructural cytochemistry by a new technique. J Histochem Cytochem 14:291.

Hafer-Macko C, Pang M, Seilhamer JJ, and Baum LG (1996). Galectin-1 is expressed by thymic epithelial cells in myasthenia gravis. Glycoconj J 13:591-597.

Hsu SM, Raine L, and Fanger H (1981). Use of avidin-biotinperoxidase complex $(A B C)$ in immunoperoxidase techniques: A comparison between $A B C$ and unlabeled antibody (PAP) procedures. J Histochem Cytochem 29:577-580.

Hunt G (1989). The role of laminin in cancer invasion and metastasis. Exp Cell Biol 57:165-176.

International Federation of Gynecology and Obstetrics (1987). Changes in definitions of clinical staging for carcinoma of the cervix and ovary. Am J Obstet Gynecol 156:236.

Liao DI, Kapadia G, Ahmed H, Vasta GR, and Herzberg O (1994). Structure of S-lectin, a developmentally regulated vertebrate beta-galactoside-binding protein. Proc Natl Acad Sci USA 91:1428-1432.

Mahanthappa NK, Cooper DNW, Barondes SH, and Schwarting GA (1994). Rat olfactory neurons can utilize the endogenous lectin, $\mathrm{L}-14$, in a novel adhesion mechanism. Development 120:1373-1384.

Pace KE, Hahn HP, Pang M, Nguyen JT, and Baum LG (2000). CD7 delivers a pro-apoptotic signal during galectin1-induced T cell death. J Immunol 165:2331-2334.

Pace KE, Lee C, Stewart PL, and Baum LG (1999). Restricted receptor segregation into membrane microdomains occurs on human $\mathrm{T}$ cells during apoptosis induced by galectin-1. $\mathrm{J}$ Immunol 163:3801-3811.

Perillo NL, Pace KE, Seilhamer JJ, and Baum LG (1995). Apoptosis of T cells mediated by galectin-1. Nature 378:736739.

Piechaczyk M, Blanchard JM, Marty L, Dani C, Panabieres F, El Sabouty S, Fort P, and Jeanteur P (1984). Posttranscriptional regulation of glyceraldehyde-3-phosphatedehydrogenase gene expression in rat tissues. Nucleic Acids Res 12:6951-6963.

Rabinovich GA, Ariel A, Hershkoviz R, Hirabayashi J, Kasai K, and Lider O (1999). Specific inhibition of T-cell adhesion to extracellular matrix and proinflammatory cytokine secretion by human recombinant galectin-1. Immunology 97:100-106.

Rorive S, Belot N, Decaestecker C, Lefranc F, Gordower L, Micik S, Maurage CA, Kaltner H, Ruchoux MM, Danguy A, Gabius HJ, Salmon I, Kiss R, and Camby I (2001). Galectin-1 is highly expressed in human gliomas with relevance for modulation of invasion of tumor astrocytes into the brain parenchyma. Glia 33:241-255.

Sanjuan X, Fernandez PL, Castells A, Castronovo V, van den Brule F, Liu FT, Cardesa A, and Campo E (1997). Differential expression of galectin 3 and galectin 1 in colorectal cancer progression. Gastroenterology 113:1906-1915.

Shimonishi T, Miyazaki K, Kono N, Sabit H, Tuneyama K, Harada K, Hirabayashi J, Kasai K, and Nakanuma Y (2001). Expression of endogenous galectin- 1 and galectin- 3 in intrahepatic cholangiocarcinoma. Hum Pathol 32:302-310.

Stojanovic D, Hughes RC, Feizi T, and Childs RA (1983). Interactions of a mammalian beta-galactoside-binding lectin with hamster fibroblasts. J Cell Biochem 21:119-127. 
Vaarala MH, Porvari K, Kyllonen A, and Vihko P (2000). Differentially expressed genes in two LNCaP prostate cancer cell lines reflecting changes during prostate cancer progression. Lab Invest 80:1259-1268.

van den Brûle F, Clausse N, Waltregny D, and Castronovo V (1999). Increased frequency of galectin-1 expression in prostatic tumor-associated capillary endothelial cells: Possible induction by prostate carcinoma cells. Angiogenesis 3:317325.

van den Brûle FA, Berchuck A, Bast RC, Liu F-T, Gillet C, Sobel ME, and Castronovo V (1994). Differential expression of the 67-kD laminin receptor and 31-kD human lamininbinding protein in human ovarian carcinomas. Eur $\mathrm{J}$ Cancer 30A:1096-1099.

van den Brûle FA, Buicu C, Baldet M, Sobel ME, Cooper DNW, Marschal P, and Castronovo V (1995). Galectin-1 modulates human melanoma cell adhesion to laminin. Biochem Biophys Res Commun 209:760-767.

van den Brûle FA, Buicu C, Berchuck A, Bast RC, Deprez M, Liu F-T, Cooper DNW, Pieters C, Sobel ME, and Castronovo $\mathrm{V}$ (1996). Expression of the 67-kD laminin receptor, galectin-1, and galectin-3 in advanced human uterine adenocarcinoma. Hum Pathol 27:1185-1191. van den Brûle FA and Castronovo V (2000). Laminin-binding lectins during cancer invasion and metastasis. In: Caron $M$ and Sève A-P, editors. Lectins and pathology. Amsterdam: Harwood Academic Publishers, 79-121.

van den Brûle FA, Waltregny D, and Castronovo V (2001). Increased expression of galectin-1 in carcinoma-associated stroma predicts poor outcome in prostate carcinoma patients. J Pathol 193:80-87.

Vespa GN, Lewis LA, Kozak KR, Moran M, Nguyen JT, Baum LG, and Miceli MC (1999). Galectin-1 specifically modulates TCR signals to enhance TCR apoptosis but inhibit IL-2 production and proliferation. J Immunol 162:799-806.

Vyakarnam A, Dagher SF, Wang JL, and Patterson RJ (1997). Evidence for a role for galectin-1 in pre-mRNA splicing. Mol Cell Biol 17:4730-4737.

Xu XC, El-Naggar A, and Lotan R (1995). Differential expression of galectin-1 and galectin-3 in thyroid tumors. Am J Pathol 147:815-822.

Zhou Q and Cummings RD (1990). The S-type lectin from calf heart tissue binds selectively to the carbohydrate chains of laminin. Arch Biochem Biophys 281:27-35. 